\title{
Subarachnoid Hemorrhage
}

National Cancer Institute

\section{Source}

National Cancer Institute. Subarachnoid Hemorrhage. NCI Thesaurus. Code C50757.

Intracranial hemorrhage into the subarachnoid space. 